\title{
Gestão Pública e Agenda 2030: uma revisão integrativa da literatura
}

\author{
Public Management and 2030 Agenda: an integrative literature review \\ Gestión Pública y Agenda 2030: una revisión integradora de la literatura
}

Recebido: 06/09/2021 | Revisado: 12/09/2021 | Aceito: 16/09/2021 | Publicado: 18/09/2021

\author{
Micaelli Lobo dos Santos \\ ORCID: https://orcid.org/0000-0001-6529-7173 \\ Universidade Federal da Fronteira Sul, Brasil \\ E-mail: micaellilobo.s@gmail.com \\ Ceyça Lia Palerosi Borges \\ ORCID: https://orcid.org/0000-0003-2818-3569 \\ Universidade Federal da Fronteira Sul, Brasil \\ E-mail: ceyca.borges@uffs.edu.br \\ Letícia da Costa e Silva \\ ORCID: https://orcid.org/0000-0001-9017-4095 \\ Universidade Federal da Fronteira Sul, Brasil \\ E-mail: leticia.csilva01@gmail.com
}

\begin{abstract}
Resumo
Objetiva-se neste estudo investigar por meio de uma revisão integrativa, a discussão científica nacional e internacional sobre a implementação da Agenda 2030 e do Programa Cidades Sustentáveis (PCS) na gestão pública, considerando os artigos publicados na base Web of Science no período de 2015 a 2020. Desta forma, foram selecionados 07 estudos que puderam contribuir para a presente pesquisa. Analisaram-se o ano da publicação do estudo, país de origem da pesquisa, idioma, revista publicada e tipo de documento, objetivo do estudo e suas contribuições. Os estudos analisados demonstram a importância da gestão pública na implementação da Agenda 2030 e/ou de outros programas ambientais e a ausência de mecanismos de avaliação e controle do desempenho das metas voltadas ao desenvolvimento sustentável. Ademais, apontam-se as parcerias multistakeholders entre as instituições de ensino superior, empresas privadas, setor público e sociedade civil como fundamentais para a concretização da agenda e/ou de outros programas que versam sobre uma gestão socioambiental.
\end{abstract}

Palavras-chave: Desenvolvimento sustentável; Parcerias multistakeholders; Programas ambientais.

\begin{abstract}
The aim of this study is to investigate, through an integrative review, the national and international scientific discussion on the implementation of the 2030 Agenda and the Sustainable Cities Program (PCS) in public administration, considering the articles published in the Web of Science database in the period of 2015 to 2020. Thus, 07 studies were selected that could contribute to this research. The year of publication of the study, country of origin of the research, language, published journal and type of document, objective of the study and its contributions were analyzed. The studies analyzed demonstrate the importance of public management in implementing the 2030 Agenda and/or other environmental programs and the absence of mechanisms for evaluating and controlling the performance of goals aimed at sustainable development. Furthermore, multistakeholder partnerships between higher education institutions, private companies, the public sector and civil society are pointed out as fundamental for the implementation of the agenda and/or other programs that deal with socio-environmental management.
\end{abstract}

Keywords: Sustainable development; Multistakeholder partnerships; Environmental programs.

\section{Resumen}

El objetivo de este estudio es investigar, a través de una revisión integradora, la discusión científica nacional e internacional sobre la implementación de la Agenda 2030 y el Programa de Ciudades Sostenibles (PCS) en la administración pública, considerando los artículos publicados en la base de datos Web of Science en el período de 2015 a 2020. Así, se seleccionaron 07 estudios que podrían contribuir a esta investigación. Se analizó el año de publicación del estudio, país de origen de la investigación, idioma, revista publicada y tipo de documento, objetivo del estudio y sus aportes. Los estudios analizados demuestran la importancia de la gestión pública en la implementación de la Agenda 2030 y / u otros programas ambientales y la ausencia de mecanismos para evaluar y controlar el desempeño de las metas orientadas al desarrollo sostenible. Además, las asociaciones de múltiples partes interesadas entre instituciones de educación superior, empresas privadas, el sector público y la sociedad civil se señalan como fundamentales para la implementación de la agenda y / u otros programas que abordan la gestión socioambiental.

Palabras clave: Desarrollo sostenible; Asociaciones de múltiples partes interesadas; Programas ambientales. 


\section{Introdução}

A questão do desenvolvimento se manifestou no século XX quando se intensificaram as preocupações com as condições de vida das pessoas, altas taxas de analfabetismo, miséria e mortalidade infantil (Souza, 2012). Entre 1950 e 1960 discutir o desenvolvimento se tornou necessário pelas flutuações econômicas que enfatizaram as situações de concentração de renda e riqueza pelo aparecimento de poucos países industrializados, agravando a dissemelhança entre os países desenvolvidos e subdesenvolvidos causada pela industrialização (Veiga, 2015). Além das questões sociais, os problemas ambientais também passaram a preocupar especialistas e instituições ao redor do mundo como pode ser visto no trabalho de Carson de 1962 (Carson, 2010) e nas tratativas da Organização das Nações Unidas (ONU) a partir da década de 1970 sobre o modelo desenvolvimento dos países e os desequilíbrios ambientais gerados.

A internacionalização desse debate promovida pela ONU torna essa entidade fundamental para a discussão de melhorias na qualidade de vida da população, respeito aos direitos humanos, progresso econômico, social e cultural a partir dos subsídios de instituições internacionais e a garantia das liberdades essenciais (Bourscheidt, 2011).

Em 1972 a Conferência das Nações sobre o Meio Ambiente e Desenvolvimento (CNUMAD), órgão da ONU, conhecida como Conferência de Estocolmo, introduz na discussão internacional a construção de um outro modelo de desenvolvimento. A CNUMAD reconheceu o balanço do impacto humano global sobre o meio ambiente e estabeleceu uma visão comum sobre os desafios da preservação ambiental e das melhorias do meio ambiente humano. Este evento contribuiu para a determinação de metas e objetivos de políticas ambientais amplas, oportunizando a implementação de uma legislação ambiental nos países, bem como o ativismo ambiental (United Nations, 2012).

O evento também permitiu a criação da Comissão Mundial de Meio Ambiente e Desenvolvimento (CMMAD), a qual publicou em 1987 o Relatório de Brundtland, denominado "Nosso Futuro Comum" que trouxe a conceitualização do desenvolvimento sustentável (Veiga, 2015), passando a ser conhecido como "aquele que atende as necessidades do presente sem comprometer a possibilidade das gerações futuras atenderem as suas próprias necessidades" (Comissão Mundial de Meio Ambiente e Desenvolvimento, 1991, p. 46).

Dentre as diversas conferências ambientais propostas pela ONU ao longo dos anos, destaca-se a Cúpula de Desenvolvimento Sustentável ocorrida em setembro de 2015 em New York, que discutiu por meio da Assembleia Geral da ONU, a adoção do documento “Transformando Nosso Mundo: a Agenda 2030 para o Desenvolvimento Sustentável”. A Agenda 2030 é um plano de ação que almeja fortalecer a paz universal, indicando 17 Objetivos de Desenvolvimento Sustentável (ODSs) e 169 metas para extinguir a pobreza e promover um padrão de vida digno para as pessoas (Organização das Nações Unidas, 2015). O fomento desta agenda deve-se principalmente pela sua relevância política em todos os países (desenvolvidos ou em desenvolvimento), especificamente após os desastres ambientais surgidos com mais frequência no século XX, a crise econômica de 2008-2009 e a pertinência das desigualdades sociais em um mundo cada vez mais globalizado (Januzzi \& De Carlo, 2018).

As metas estabelecidas pela Agenda 2030 demandam uma abordagem integrada, sistêmica e resiliente para a promoção do desenvolvimento sustentável (Brandi, 2018). Posto isto, o governo assume um papel primordial para a concretização do documento e/ou de outros programas socioambientais, especialmente no âmbito local, uma vez que o setor público define e implementa ações capazes de priorizar objetivos e metas da agenda no planejamento e orçamento público, além da promoção do engajamento da sociedade civil nos debates pertinentes (Montolli, Cançado, \& Claus, 2021).

Diante do exposto, a presente pesquisa tem como objetivo investigar por meio de uma revisão integrativa, a discussão científica nacional e internacional sobre a implementação da Agenda 2030 e de outros programas baseados no modelo de cidades sustentáveis na gestão pública, considerando os artigos publicados na base Web of Science no período de 2015 a 2020. 


\section{Metodologia}

A revisão integrativa é considerada um método de revisão que sintetiza a literatura empírica ou teórica a fim de apresentar o estado da arte sobre determinado assunto e contribuir para o desenvolvimento de uma teoria com aplicabilidade direta para a prática (Whittemore \& Knafl, 2005).

De acordo com Botelho, Cunha e Macedo (2011) a revisão integrativa segue uma sucessão de etapas bem definidas, sendo elas: i) identificação do tema e seleção da questão de pesquisa, ii) estabelecimentos dos critérios de inclusão e exclusão, iii) identificação dos estudos pré-selecionados, iv) categorização dos estudos selecionados, v) análise e interpretação dos resultados e vi) apresentação da revisão/síntese do conhecimento.

Na primeira etapa define-se um problema e a formulação de uma pergunta de pesquisa, seguida da definição dos descritores da estratégia de busca e os bancos de dados utilizados (ibid., 2011). Logo, o problema da presente pesquisa ficou definido como: Quais as discussões científicas nacionais e internacionais sobre o papel da gestão pública na implementação da Agenda 2030 e de outros programas que versam sobre as cidades sustentáveis?

Em relação às estratégias de busca, definiu-se a base de dados Web of Science Coleção Principal, que possui um alcance internacional com documentos publicados em revistas conceituadas cientificamente com elevados níveis de qualidade. Dada a investigação científica sobre a Gestão Pública, Agenda 2030 e programas que versam sobre as cidades sustentáveis, estabeleceram-se os pares de descritores para que a base retornasse trabalhos que permeiam a temática. Assim, escolheram-se os pares de descritores em português “Gestão pública” AND “Agenda 2030” e "Gestão pública" AND "Programa Cidades Sustentáveis". Em inglês "Public Management” AND "2030 Agenda" e "Public Management” AND "Sustainable Cities Program". E em espanhol “Gestión Pública” AND “Agenda 2030” e “Gestión Pública” AND "Programa Ciudades Sostenibles".

Quanto à segunda etapa, ela consiste no estabelecimento de critérios claros e objetivos de inclusão e exclusão que permite uma coleta de amostra significativa. Tais critérios são aplicados no momento da busca na base de dados (Botelho, Cunha, \& Macedo, 2011). Para a presente pesquisa, optou-se por critérios envolvendo o período de publicação dos artigos e o tipo de documento. Assim, o período foi definido a partir de setembro de 2015, em virtude do acontecimento da Cúpula de Desenvolvimento Sustentável ocorrida em setembro de 2015 em New York, na qual foi discutida pela Assembleia Geral da ONU, a adoção do documento "Transformando Nosso Mundo: a Agenda 2030 para o Desenvolvimento Sustentável” (ONU, 2015). Quanto à escolha do tempo limite da busca, definiu-se até o ano de 2020, considerando que após este período iniciaram-se as análises desta pesquisa. Em relação à seleção do material analisado, isto é, os tipos de documentos, definiu-se a busca por documentos em formato de artigos e artigos de revisão. Os descritores foram buscados nos títulos, resumos e/ou palavras-chave, sendo que na base Web of Science Coleção Principal, este conjunto é denominado tópico.

A terceira etapa é responsável pela leitura rigorosa dos títulos, resumos e palavras-chave ${ }^{1}$ para que possamos realizar a pré-seleção ou a seleção propriamente dita dos estudos (Botelho, Cunha \& Macedo, 2011). Após este processo, uma planilha no Microsoft Excel® foi preenchida com o levantamento das seguintes informações: i) ano da publicação, ii) país de origem do estudo, iii) idioma, iv) revista publicada, v) título do documento, vi) tipo de documento (artigo ou review), vii) objetivo do estudo, viii) DOI, ix) link do trabalho, $\mathrm{x}$ ) possíveis contribuições ${ }^{2}$ para a presente pesquisa e xi) observações gerais.

Após as leituras e preenchimento da planilha, excluíram-se os estudos que não tratavam sobre a gestão pública, Agenda 2030 e outros programas que versam sobre as cidades sustentáveis, bem como aqueles que não versaram sobre a Agenda 2030

\footnotetext{
${ }^{1}$ Nos casos em que o título, resumo e/ou palavras-chave não foram suficientes para a seleção do estudo, realizou-se a leitura na íntegra do documento;

${ }^{2}$ Para responder se o artigo contribui ou não para esta pesquisa, em alguns casos (quando os resultados não foram contemplados no resumo do estudo) foi necessária a leitura dos resultados e considerações finais.
} 
como um todo ${ }^{3}$. Os documentos teóricos também foram descartados, uma vez que esta pesquisa prioriza os trabalhos empíricos na área em estudo. Após essas exclusões, o estudo obteve a quantidade final de artigos selecionados sendo retirados deles informações adicionais referentes aos autores e procedimentos metodológicos.

A quarta etapa sistematiza os dados coletados nas fases anteriores, a fim de possibilitar uma análise concisa e objetiva (Botelho, Cunha \& Macedo, 2011). Portanto, utilizou-se a categorização dos estudos selecionados por meio de duas categorias de análise, sendo elas: i) estudos que retratam o papel da gestão pública na implementação da Agenda $2030^{4}$ e/ou de outros programas que versam sobre cidades sustentáveis e ii) estudos que discutem as estratégias utilizadas na implementação da Agenda 2030 e/ou de outros programas que versam sobre cidades sustentáveis.

Ao categorizar os estudos na etapa anterior, os trabalhos foram analisados e interpretados de forma quantitativa e qualitativa, consistindo assim, na quinta etapa proposta por Botelho, Cunha e Macedo (2011). Logo, na análise quantitativa, os dados foram sistematizados no Microsoft Excel ${ }^{\circledR}$ em forma de quadros, tabelas e gráficos. Na análise qualitativa, priorizou-se a análise de conteúdo dos estudos selecionados a partir das categorias de análise estabelecidas na quarta etapa. Reuniram-se as informações do título, objetivo, metodologia e contribuições para a pesquisa, a fim de compreender o estado da arte sobre a gestão pública, Agenda 2030 e outros programas que salientam as cidades sustentáveis. Possibilitou-se ainda nesta análise, a identificação das lacunas existentes que oportunizam o surgimento de novos estudos nesta área. E, por fim, a sexta etapa permite a apresentação e síntese do conteúdo dos estudos selecionados, de modo que novos estudos possam reaplicar a metodologia dos trabalhos (Botelho, Cunha, \& Macedo, 2011).

\section{Resultados e Discussão}

\subsection{Análise quantitativa da Gestão Pública, Agenda 2030 e Programa Cidades Sustentáveis nos estudos selecionados}

A primeira busca realizada na base Web of Science trouxe um resultado de 183 artigos. Entretanto, foram descartados 154 estudos que não discorriam sobre a gestão pública e a Agenda 2030 ou gestão pública e outros programas que versam sobre as cidades sustentáveis, 18 estudos foram descartados por serem bibliográficos e 04 que tratavam os ODSs de forma isolada.

Logo, restaram 07 artigos que atendem ao objetivo desta pesquisa, conforme demonstra a Tabela 1 a seguir.

\footnotetext{
${ }^{3} \mathrm{O}$ critério de descarte dos estudos que trabalham com ações isoladas de um ou alguns ODSs da Agenda 2030 leva em consideração as premissas dos Objetivos de Desenvolvimento Sustentável (ODSs), que buscam salientar que os ODSs "são integrados e indivisíveis, e mesclam, de forma equilibrada, as três dimensões do desenvolvimento sustentável" (ONU, 2015, p. 03).

${ }^{4}$ Cabe aqui destacar que quando se fala em implementação da Agenda 2030, consideram-se os trabalhos empíricos que envolvem um processo de aplicação da agenda como um todo e não ações isoladas que sinalizam a implementação de um ou outro ODS.
} 
Tabela 1 - Quantidade de estudos por descritores encontrada na base Web of Science Coleção Principal no período de 20152020.

\begin{tabular}{|c|c|}
\hline Descritores & Quantidade \\
\hline “Gestão Pública” AND “Agenda 2030” & 0 \\
\hline "Gestão pública" AND "Programa Cidades Sustentáveis" & 0 \\
\hline "Public Management” AND “2030 Agenda” & 5 \\
\hline $\begin{array}{c}\text { "Public Management” AND "Sustainable Cities } \\
\text { Program” }\end{array}$ & 2 \\
\hline “Gestión Pública” AND “Agenda 2030” & 0 \\
\hline $\begin{array}{c}\text { "Gestión Pública” AND "Programa Ciudades } \\
\text { Sostenibles" }\end{array}$ & 0 \\
\hline Total & $\underline{7}$ \\
\hline
\end{tabular}

Fonte: Autores (2021).

A seleção envolveu somente artigos recuperados a partir do uso dos descritores em inglês. Destaca-se que dentre estes 07 documentos, não houve repetições entre os pares de descritores. Assim, a partir desta quantidade de publicações, analisaramse as seguintes informações: ano de publicação, idioma, tipo de documento e a fonte do documento.

O ano com o maior número de publicações foi o de 2020, com um total de quatro estudos e nos anos de 2015,2016 e 2018 foram registrados uma publicação em cada ano, totalizando três estudos. Dessa forma, após a publicação da Agenda 2030 em 2015 observa-se um aumento de pesquisas relacionadas ao tema com o passar dos anos. Os quatro estudos publicados em 2020 tratam da Agenda 2030, especificamente, reforçando que há no mundo uma tentativa de atender os ODS. Sendo esses objetivos sugeridos por uma entidade internacional altamente reconhecida e respaldada, conjuntamente com a cobrança cada vez mais intensa de que as autoridades públicas tomem providências quanto aos problemas ambientais, não é surpresa que o número de publicações aumente com o passar dos anos.

Quanto à quantidade de publicações por idioma, dentre os 07 estudos selecionados, 04 estão na língua inglesa, 02 na língua espanhola e um em português. A prevalência de estudos em inglês está tanto na indexação da Web of Science ser nesse idioma, como no uso oficial dele para a comunicação entre pesquisadores de diferentes países. Quanto ao tipo de documentos, todas as publicações são artigos científicos.

Em relação à fonte e país de origem dos estudos, a Tabela 2 apresenta a quantidade de publicações por revista e país. 
Tabela 2 - Quantidade de publicações na base Web of Science Coleção Principal no período de 2015-2020 por revista e país de origem dos estudos.

\begin{tabular}{|c|c|c|c|c|c|c|}
\hline \multirow{2}{*}{ Revista } & \multicolumn{6}{|c|}{ País de origem dos estudos } \\
\hline & Brasil & Espanha & Irlanda & México & Suécia & Total \\
\hline $\begin{array}{c}\text { Administração Pública e } \\
\text { Gestão Social }\end{array}$ & 1 & & & & & 1 \\
\hline $\begin{array}{c}\text { Brazilian Journal of } \\
\text { Operations \& Production } \\
\text { Management }\end{array}$ & 1 & & & & & 1 \\
\hline $\begin{array}{l}\text { Environment, } \\
\text { Development and } \\
\text { Sustainability }\end{array}$ & & & & & 1 & 1 \\
\hline $\begin{array}{c}\text { Investigación y } \\
\text { pensamiento crítico }\end{array}$ & & 1 & & & & 1 \\
\hline $\begin{array}{l}\text { Revista Geográfica da } \\
\text { América Central }\end{array}$ & & & & 1 & & 1 \\
\hline Sustainability & & 1 & 1 & & & 2 \\
\hline Total & 2 & 2 & 1 & 1 & 1 & 7 \\
\hline
\end{tabular}

Fonte: Autores (2021).

Dentre as publicações em revistas científicas nacionais e internacionais, o Brasil e a Espanha foram os países que mais publicaram, com dois trabalhos no total, cada um deles. Enquanto os outros países tiveram uma publicação cada. Destaca-se que as publicações brasileiras foram todas em periódicos nacionais, sendo eles, o Brazilian Journal of Operations \& Production Management e a Revista de Administração Pública e Gestão Social. Interessante verificar que o escopo desses periódicos não passa necessariamente pelo tema da sustentabilidade, porém por ser um assunto urgente ele vem sendo estudado cada vez mais pelas áreas correlatas à gestão.

A revista Sustainability teve o maior registro de publicações (02 estudos) justamente pelo seu escopo versar sobre a sustentabilidade e o desenvolvimento sustentável, além de possuir afiliados renomados como a Sociedade de Ecologia Urbana, o Consórcio Canadense de Pesquisa e Inovação de Trânsito Urbano e o Conselho Internacional de Pesquisa e Inovação em Construção (Multidisciplinary Digital Publishing Institute, 2021). A origem dos estudos publicados nesta revista foi a Espanha e a Irlanda, denotando o caráter internacional do periódico. Os outros periódicos tiveram uma publicação em cada conforme visto na Tabela 2.

\subsection{Análise qualitativa da Gestão Pública, Agenda 2030 e Programa Cidades Sustentáveis nos estudos selecionados}

\subsubsection{Estudos que enfatizam o papel da gestão pública na implementação da Agenda 2030 e/ou outros programas que}

\section{versam sobre as cidades sustentáveis}

O Quadro 1 apresenta a seleção de 04 estudos dos 07 artigos selecionados, que estão voltados à primeira categoria de análise da revisão integrativa. 
Quadro 1 - Análise dos estudos que enfatizam o papel da gestão pública na implementação da Agenda 2030 e/ou de outros programas que versam sobre as cidades sustentáveis

\begin{tabular}{|c|c|c|c|c|c|c|}
\hline Autores & Estudos & Título & País & Revista & $\begin{array}{c}\text { Tipo de } \\
\text { documento }\end{array}$ & Objetivo \\
\hline $\begin{array}{l}\text { Palm e Lilja } \\
\quad(2020)\end{array}$ & Estudo 01 & $\begin{array}{l}\text { On the road to Agenda } \\
2030 \text { together in a complex } \\
\text { alliance of Swedish public } \\
\text { authorities }\end{array}$ & Suécia & $\begin{array}{l}\text { Environment, } \\
\text { Development } \\
\quad \text { and } \\
\text { Sustainability }\end{array}$ & Artigo & $\begin{array}{l}\text { Aumentar a compreensão do Desenvolvimento de Organização Dialógica (DOD) } \\
\text { como um método para promover a capacidade de inovação em órgãos públicos, que } \\
\text { pode ajudar a criar boas condições para o desenvolvimento das atividades dos } \\
\text { órgãos públicos e a capacidade de contribuir para os objetivos da Agenda } 2030 \text {. }\end{array}$ \\
\hline Moreira (2018) & Estudo 02 & $\begin{array}{c}\text { Application of the } \\
\text { sustainable logistics plan in } \\
\text { the public administration }\end{array}$ & Brasil & $\begin{array}{l}\text { Brazilian } \\
\text { Journal of } \\
\text { Operations \& } \\
\text { Production } \\
\text { Management }\end{array}$ & Artigo & $\begin{array}{l}\text { O principal objetivo deste estudo, trata-se do princípio constitucional do } \\
\text { desenvolvimento sustentável - previsto no artigo 225, da Constituição Federal } \\
\text { Brasileira - e como ele tem sido aplicado na gestão socioambiental do Poder } \\
\text { Judiciário do Estado do Rio de Janeiro, coerente com os pressupostos da Agenda } \\
\text { 2030, avaliando as principais iniciativas em curso quanto à incorporação dos } \\
\text { Objetivos de Desenvolvimento Sustentável (ODS). }\end{array}$ \\
\hline $\begin{array}{l}\text { Fragoso, } \\
\text { Arredondo e } \\
\text { García (2016) }\end{array}$ & Estudo 03 & $\begin{array}{l}\text { Ciudad rural sustenable de } \\
\text { Jaltenango: aciertos y } \\
\text { desaciertos en el } \\
\text { ordenamiento territorial }\end{array}$ & México & $\begin{array}{l}\text { Revista } \\
\text { Geográfica da } \\
\text { América } \\
\text { Central }\end{array}$ & Artigo & $\begin{array}{c}\text { Analisar os resultados do Programa Cidades Rurais Sustentáveis (CRS) } \\
\text { implementado pelo governo de Chiapas. }\end{array}$ \\
\hline $\begin{array}{l}\text { Oliveira, } \\
\text { Trindade e } \\
\text { Pereira }(2015)\end{array}$ & Estudo 04 & \begin{tabular}{|} 
Políticas Públicas Indutoras \\
do Desenvolvimento \\
Sustentável Local: Um \\
Estudo Sobre o Programa \\
Município VerdeAzul na \\
Região do Grande ABC
\end{tabular} & Brasil & $\begin{array}{l}\text { Administração } \\
\text { Pública e } \\
\text { Gestão Social }\end{array}$ & Artigo & $\begin{array}{c}\text { Apresentar um estudo exploratório sobre o programa Município VerdeAzul, } \\
\text { instituído em } 2007 \text { pelo governo do estado de São Paulo como incentivo aos } \\
\text { municípios que atuam na melhoria das condições ambientais. }\end{array}$ \\
\hline
\end{tabular}

Fonte: Autores (2021). 
Conforme demonstrado no Quadro 1, os resultados apontam que dos 04 artigos selecionados para esta categoria, 02 são realizados no Brasil, 01 na Suécia e 01 no México. Destacam-se, portanto, os estudos brasileiros nesta categoria de análise. Observa-se também que dois deles focam no estudo das ações de programas sustentáveis implementadas em municípios, sendo um trabalho realizado no México e outro no Brasil.

O estudo 01 teve como objetivo aumentar a compreensão do Desenvolvimento de Organização Dialógica (DOD) como um método de promoção da capacidade de inovação em órgãos públicos da Suécia, capaz de contribuir para os objetivos da Agenda 2030. Para responder o problema de pesquisa, o trabalho assumiu a forma de um estudo de caso qualitativo e de abordagem dedutiva, com a extração de dados empíricos. O estudo permeou o Projeto Innovation Lab 2030 que foi formado e implementado por meio da aplicação da Teoria do DOD $^{5}$ com o objetivo de aumentar a capacidade de inovação de três órgãos públicos, a fim de aumentar sua capacidade de contribuição para o alcance dos ODSs. Essas autoridades governamentais envolvidas no projeto, expressaram a necessidade da Suécia ser líder na implementação da Agenda 2030. Como resultado, o estudo reconheceu que as lideranças administrativa e adaptativa devem trabalhar mutuamente, para que as organizações funcionem corretamente. Identifica-se ainda, a necessidade de uma governança em rede para aumentar a capacidade das autoridades em gerenciar os ajustes basilares à implementação efetiva da Agenda 2030.

O estudo 02 considerou a complexidade e o tamanho da estrutura do Tribunal de Justiça do Estado do Rio de Janeiro (TJERJ) e propôs uma mudança na cultura organizacional deste órgão. Sendo assim, implementou-se um planejamento socioambiental a partir da adesão da Agenda A3P e da elaboração do Plano de Logística Sustentável (PLS). Buscou-se por meio de um estudo de caso, pesquisas exploratórias e documentais, uma melhor compreensão dos ODSs e analisou seu cumprimento na gestão socioambiental do TJERJ no Brasil, identificando as principais iniciativas desenvolvidas e sua efetiva contribuição. Os resultados da pesquisa apontaram que o TJERJ incorporou iniciativas sustentáveis em sua gestão, classificadas em diversos eixos temáticos voltados aos ODSs. Ademais, verificou-se no estudo a importância do estabelecimento de ferramentas de monitoramento e avaliação das políticas públicas, priorizando uma governança pública sustentável respaldada pelo artigo 225 da Constituição Federal Brasileira de 1998 que dispõe sobre o desenvolvimento sustentável.

O estudo 03 buscou analisar os resultados do Programa Cidades Rurais Sustentáveis (CRS) implementado pelo Governo do Estado de Chiapas, México, tendo como análise a Cidade Rural Sustentável Jaltenango (CRSJ), construída no município de Angel Albino Corzo em 2012. A metodologia seguiu uma abordagem mista, a partir de um método qualitativo e quantitativo e foram aplicadas entrevistas para alguns habitantes, líderes e outros atores locais, a fim de conhecer e avaliar a realidade econômica, gestão social, territorial e municipal. Apesar do trabalho não mencionar a estratégia de pesquisa do estudo de caso, compreende-se que o foco na CRSJ caracteriza que a pesquisa teve como meio esse tipo de estudo. Os resultados do trabalho evidenciaram que o Programa CRS é uma alternativa de solução para os problemas que afligem a população de Jaltenango, entretanto, apesar dos avanços, alguns eixos do programa mostraram lacunas a serem preenchidas, tais como: serviços de saúde, segurança pública, superlotação em pequenos espaços de moradias, ausência de um regime de propriedade habitacional, desemprego, ausência do reconhecimento jurisdicional da CRSJ como parte do município por Angel Albino Corzo, entre outros.

$\mathrm{O}$ artigo 04 identifica quais os critérios das três principais diretivas do Programa Município VerdeAzul ${ }^{6}$ estão sendo atendidos adequadamente pelos municípios brasileiros que compõem a região paulista do ABC. Trata-se de uma pesquisa exploratória baseada na pesquisa documental para a coleta de dados. Apesar do trabalho não mencionar a estratégia de pesquisa

${ }^{5} \mathrm{O}$ modelo DOD entende as organizações como sistemas abertos que precisam ter seus elementos alinhados às mudanças do ambiente competitivo. A situação atual da organização e/ou comunidade deve ser diagnosticada para estabelecer quais aspectos necessitam ser alterados e quais ferramentas são ideais para alcançar os melhores resultados possíveis (Bushe \& Marshak, 2015).

${ }^{6}$ Trata-se de um programa com o objetivo de estimular e auxiliar as prefeituras paulistas na elaboração e execução de suas políticas públicas estratégicas para o desenvolvimento sustentável do estado de São Paulo (Governo do Estado de São Paulo, 2021). 
do estudo de caso, compreende-se que o foco nos municípios do $\mathrm{ABC}$ paulista caracteriza que a pesquisa teve como meio esse tipo de estudo. Os documentos utilizados foram as Resoluções extraídas da Secretaria Estadual do Meio Ambiente (SMA) referentes ao Programa Município VerdeAzul, os Planos de Ação preenchidos no Sistema de Meio Ambiente por cada um dos sete municípios, o resultado publicado pelo governo do Estado de São Paulo no Ranking Ambiental, as informações encontradas nos websites das prefeituras desses municípios e os Relatórios de Águas Superficiais e de Resíduos Sólidos, ambos da CETESB. Como resultados, identificaram-se as diretivas mais importantes do projeto, sendo estas: Esgoto Tratado, Resíduos Sólidos e Educação Ambiental.

O estudo demonstrou que os municípios de São Bernardo do Campo, Diadema, Mauá e Rio Grande da Serra estão com baixa capacidade de tratamento de esgoto. Quanto aos resíduos sólidos, é necessário a avaliação de novos locais para despejar os resíduos, uma vez que a maioria deles são despejados no aterro de Mauá, com exceção do município de Santo André que já possui aterro próprio. Em relação à diretiva de educação ambiental, ressalta-se que esta questão entrou no planejamento educacional dos municípios analisados, sendo que há pelo menos um centro de educação ambiental por município.

\subsubsection{Estudos que discutem as estratégias utilizadas na implementação da Agenda 2030 e/ou outros programas que} versam sobre as cidades sustentáveis

O Quadro 2 apresenta os 03 estudos, que estão voltados à segunda categoria de análise da revisão integrativa. 
Quadro 2 - Análise dos estudos que enfatizam as estratégias utilizadas na implementação da Agenda 2030 e/ou de outros programas que versam sobre as cidades sustentáveis

\begin{tabular}{|c|c|c|c|c|c|c|}
\hline Autores & Estudo & Título & País & Revista & $\begin{array}{c}\text { Tipo de } \\
\text { documento }\end{array}$ & Objetivo \\
\hline $\begin{array}{c}\text { Soberón, } \\
\text { Sánchez- } \\
\text { Chaparro, } \\
\text { Urquijo e } \\
\text { Pereira }(2020)\end{array}$ & Estudo 05 & $\begin{array}{c}\text { Introducing an Organizational } \\
\text { Perspective in SDG Implementation } \\
\text { in the Public Sector in Spain: The } \\
\text { Case of the Former Ministry of } \\
\text { Agriculture, Fisheries, Food and } \\
\text { Environment }\end{array}$ & Espanha & Sustainability & Artigo & $\begin{array}{l}\text { Introduzir uma perspectiva organizacional em um processo } \\
\text { participativo e prioritário de ODS realizado por uma organização } \\
\text { pública: o antigo Ministério da Agricultura, Pesca, Alimentação, } \\
\text { Pesca, Alimentação e Meio Ambiente da Espanha (MAPAMA). }\end{array}$ \\
\hline $\begin{array}{l}\text { Paz e Cuenca } \\
\quad(2020)\end{array}$ & Estudo 06 & $\begin{array}{l}\text { Gobernanza global y los objetivos } \\
\text { de desarrollo sostenible en España }\end{array}$ & Espanha & $\begin{array}{l}\text { Investigación y } \\
\text { pensamiento } \\
\text { crítico }\end{array}$ & Artigo & $\begin{array}{l}\text { Abordar a partir de uma perspectiva crítica a governança global, } \\
\text { como um processo de confluência e cooperação entre os múltiplos } \\
\text { atores públicos, privados, do terceiro setor e da sociedade civil, na } \\
\text { qual a fragmentação de poderes tem sido uma qualidade desse } \\
\text { processo. Além de expor a evolução de Governança dos Objetivos } \\
\text { de Desenvolvimento Sustentável (ODS) na Espanha durante o } \\
\text { período } 2015-2020 .\end{array}$ \\
\hline $\begin{array}{l}\text { Banerjee, } \\
\text { Murphy e } \\
\text { Walsh (2020) }\end{array}$ & Estudo 07 & $\begin{array}{l}\text { Perceptions of Multistakeholder } \\
\text { Partnerships for the Sustainable } \\
\text { Development Goals: A Case Study } \\
\quad \text { of Irish Non-State Actors }\end{array}$ & Irlanda & Sustainability & Artigo & $\begin{array}{c}\text { Explorar como os membros de organizações da sociedade civil e do } \\
\text { setor privado percebem as possibilidades e desafios das parcerias } \\
\text { multistakeholders no alcance dos ODSs na Irlanda. }\end{array}$ \\
\hline
\end{tabular}

Fonte: Autores (2021). 
No caso dos artigos desta categoria, todos foram realizados em países europeus, em especial na Espanha com 02 trabalhos, conforme demonstrado no Quadro 2. É interessante observar que os estudos dessa categoria focaram em objetos de pesquisa mais amplos como um ministério em sua totalidade, ou os ODS considerados em um determinado país, essa diferença em relação à categoria anterior está na consideração da Agenda 2030 como uma estratégia a ser considerada por múltiplas partes da sociedade que não só os órgãos públicos.

O artigo 05 realizou um estudo de caso no Ministério da Agricultura, Pesca, Alimentação, Pesca, Alimentação e Meio Ambiente (MAPAMA) da Espanha, cuja análise central esteve pautada no processo de priorização de aspectos sustentáveis dentro da organização supramencionada. $\mathrm{O}$ trabalho, primeiramente i) priorizou os aspectos sustentáveis do MAPAMA por meio de uma revisão documental direcionada aos documentos-chave atrelados à implementação dos ODSs da Agenda 2030, entre outros documentos, depois ii) realizou um diagnóstico participativo, elaborado a partir de nove oficinas temáticas que discutiram as metas priorizadas dos ODSs, ações voltadas a cada um deles, fatores de sucesso e limitações e, por último iii) validou a apresentação do relatório rascunho para todas as unidades organizacionais nas oficinas.

Como resultado, o estudo 05 possibilitou a análise das competências de sustentabilidade das unidades organizacionais do MAPAMA, que por sua vez, puderam compreender sua parte de responsabilidade na implementação da Agenda 2030. Assim, dada a análise das competências, cada unidade organizacional reconheceu o seu papel e relacionamento com metas específicas dos ODSs e a sua possível contribuição na agenda. Tal contribuição foi avaliada por meio de duas perspectivas: a relevância da meta dos ODSs segundo às políticas públicas vigentes e ao nível de responsabilidade do ministério em relação a cada ODSs. Desta maneira, foi atribuída uma escala de contribuição de cada ODSs em três níveis: fraco, médio e forte. Os autores analisaram o número de unidades organizacionais envolvidas no cumprimento das metas de ODSs categorizadas como fortes, indicando a transversalidade da Agenda 2030.

O estudo 06 utilizou uma dupla metodologia: i) revisão bibliográfica sistemática da literatura científica sobre governança, Objetivos de Desenvolvimento do Milênio (ODM) Objetivos de Desenvolvimento Sustentável (ODSs) e Covid-19 e ii) pesquisa documental na base de dados das Nações Unidas, Banco Mundial, União Europeia e Governo da Espanha. Os resultados enfatizaram a conceitualização da governança pelas principais organizações pesquisadas (Programa das Nações Unidas para o Desenvolvimento - PNUD, União Europeia - UE, Organização para a Cooperação e Desenvolvimento Econômico - OCDE, Banco Mundial e Comissão de Governança Global), além de expor o planejamento e implementação da Agenda 2030 na Espanha por meio de planos de governos distintos no período de 2015 a 2020. Destaca-se aqui, que a pesquisa buscou evidenciar o impacto da Covid-19 no cumprimento dos ODSs por meio da aprovação do Segundo Relatório de Progresso "Reconstruindo a implementação da Agenda 2030 na Espanha". Os autores demonstraram que na Espanha, a implementação dos ODSs acelerou nos dois últimos anos (2018 e 2019), ainda que os resultados alcançados sejam insuficientes. Logo, faz-se necessário uma estratégia nacional de desenvolvimento sustentável e apoios financeiros que torne realidade este compromisso político. Ressalta-se ainda, que com a crise atual provocada pela Covid-19, os motores crescimento e a distribuição de renda, serão afetados e que esforços adicionais serão necessários para implementar políticas públicas eficazes.

O estudo 07 explorou a forma como os membros da sociedade civil organizada e o setor privado percebem as possibilidades e desafios das parcerias multistakeholders que evoluem na Irlanda para alcançar os ODSs. O método de pesquisa foi qualitativo uma vez que se baseia na contextualização e interpretação das diversas perspectivas. Utilizou-se também, uma pesquisa documental com informações sobre parcerias multistakeholders e o porquê e como as Nações Unidas identificaram essas parcerias como importantes para a implementação dos ODSs. A observação participante no Fórum Político de Alto Nível da ONU de 2018 e 2019 contribuiu para a identificação dos tipos de atores que participaram na revisão do progresso da implementação dos ODSs globais e da Irlanda. Aplicaram-se entrevistas semiestruturadas com 14 especialistas-chave e membros seniores de diferentes organizações e da sociedade civil, grupos ambientais, comércio, sindicatos e organizações que promovem 
interesses comerciais em comunidades locais na Irlanda. Os resultados revelam que há muitos objetivos estabelecidos e pouca consciência de fato destes objetivos. A pesquisa demonstra que os stakeholders perseguem os ODS de forma fragmentada, o que inviabiliza o viés holístico da Agenda 2030, assim como seus princípios fundamentais de universalidade e indivisibilidade.

\subsection{Discussão sobre o tema Gestão Pública, Agenda 2030 e Programas Cidades Sustentáveis}

Dentre os 07 estudos encontrados na revisão integrativa, há quase que um equilíbrio entre as duas categorias de análise. Enquanto quatro deles buscam salientar o papel da gestão pública como um todo na implementação da Agenda 2030 (02 estudos) e na efetivação de outros programas que versam sobre as cidades sustentáveis (02 estudos), três explanam estratégias de implementação da Agenda 2030 em que a gestão pública é considerada apenas uma parte dentre as outras necessárias para dar cabo aos objetivos da Agenda.

Ao explanar o tema em análise, diversas metodologias são empregadas pelos sete estudos selecionados. As pesquisas de Soberón, Sánchez-Chaparro, Urquijo e Pereira (2020), Palm e Lilja (2020) e Moreira (2018) assumem a forma de um estudo de caso e a pesquisa de Fragoso, Arredondo e García (2016) configura-se como um estudo de campo. Por sua vez, as publicações de Paz e Cuenca (2020), Banerjee, Murphy e Walsh (2020) e Oliveira, Trindade e Pereira (2015) são classificadas como pesquisas documentais. Entretanto, ao analisar os estudos é possível classificar os trabalhos de Fragoso, Arredondo e García (2016), Oliveira, Trindade e Pereira (2015) e Soberón, Sánchez-Chaparro, Urquijo e Pereira (2020) como estudos de caso também ao restringirem suas pesquisas em instituições ou cidades. Além disso, apesar de alguns estudos não explicitarem, é possível caracterizar que seis deles, exceto o de Fragoso, Arredondo e García (2016), também se baseiam na pesquisa documental, uma vez que a análise do tema Agenda 2030 ou de outros programas sustentáveis relacionados com gestão pública demanda a consideração de documentos institucionais e/ou legais.

A recorrência da escolha do estudo de caso nas investigações se dá pela oportunidade que o método oferece em permite verificar como as práticas e as ações voltadas à implementação da Agenda 2030 e de outros programas ambientais estão ocorrendo ou sendo considerados, tendo em vista que o conhecimento da realidade permite analisar a campo o local de aplicação e discussão das diretivas da agenda e/ou dos programas. Em relação aos esforços empreendidos nas pesquisas para a implementação da Agenda 2030 e de outros programas ambientais, os resultados de Soberón, Sánchez-Chaparro, Urquijo e Pereira (2020) acentuam que os estudos de caso são fundamentais para estudar novos campos, como a implementação de ODSs no setor público, pois permitem ao pesquisador ter uma compreensão mais profunda do sujeito explorado. Nos achados dos autores, o estudo de caso permitiu a identificação das necessidades de colaboração interna na execução dos ODSs, o que possibilitou a compreensão de forças de condução e contenção no início das mudanças organizacionais necessárias. Ademais, os processos participativos revelaram-se essenciais para a reprodução de dinâmicas de colaboração para a adoção da Agenda 2030. Corroborando, Palm e Lilja (2020) evidenciam que o estudo de caso possui maior potencial de compreensão das práticas de Desenvolvimento Organizacional Dialógicas (DOD) desempenhadas no enfrentamento de situações complexas e desafios relacionados aos ODSs.

Quando o estudo de caso é somado à pesquisa documental há a possibilidade de uma exploração do tema pesquisado, mas cujos resultados necessitam ser mais aprofundados a partir da aplicação de outras ferramentas de coleta de dados, como apontam Oliveira, Trindade e Pereira (2015). Esses autores revelam a necessidade de estudos futuros que complementam suas análises, por meio da realização de entrevistas com os gestores municipais para conhecer a realidade in loco da implementação do programa analisado em sua pesquisa. Sendo assim, percebe-se que o uso da triangulação de métodos para investigar o tema, aumenta a validação de resultados em pesquisas da área de ciências sociais (Patton, 2002). Tal triangulação foi utilizada nas investigações de Banerjee, Murphy e Walsh (2020), de Fragoso, Arredondo e García (2016) e Palm e Lilja (2020), os quais aplicaram entrevistas semiestruturadas com o grupo representante do ODS Nacional do Fórum de Stakeholders da Irlanda e com 
habitantes, líderes e outros atores locais representantes da Cidade Rural Sustentável de Jatelnango/México, e com representantes de órgãos públicos da Suécia, respectivamente.

Dentre as pesquisas que focaram no estudo da Agenda 2030 considerando todos os stakeholders, os três da segunda categoria somados ao de Palm e Lilja (2020) que focou em três órgão públicos da Suécia utilizaram como instrumentos a aplicação de oficinas temáticas voltadas aos ODSs da Agenda 2030, ou seja, realizaram pesquisas participativas por meio da aplicação de ferramentas em que os objetos e sujeitos da pesquisa são reunidos para a construção coletiva de dados sobre determinadas realidades (Freitas, Freitas e Dias, 2012).

A utilização de oficinas por parte desses autores sinaliza as ações participativas não só dentro dos limites da gestão pública, mas também considerando outros participantes importantes para a implementação do documento supramencionado. Assim o uso de ferramentas como o diagnóstico participativo atende a necessidade dos estudos realizados em torno de temas da sustentabilidade, uma vez que envolve a participação de diferentes atores e demanda a construção de conhecimento conjunto, como defende Muiños (2006). Por isso, o uso dessa técnica promoveu, conforme os autores, a construção de um conhecimento comum em torno das ações ambientais de cada parte envolvida, o consenso em torno de conceitos e temas, a relevância do desenvolvimento sustentável em suas atividades e para o futuro e o reconhecimento e compartilhamento do papel de cada um no alcance dos objetivos da Agenda 2030.

Soberón, Sánchez-Chaparro, Urquijo e Pereira (2020) conseguiram com a aplicação do diagnóstico participativo uma compreensão mais detalhada das partes estudadas sobre a implementação da Agenda 2030, bem como fatores de sucesso e limitações a fim de coletar sugestões e promover uma colaboração interna entre unidades organizacionais envolvidas no processo. Desta maneira, os autores defendem a metodologia de oficinas como uma pesquisa participativa que pode ser aplicada em diferentes áreas, incluindo nos estudos organizacionais. E o estudo de Palm e Lilja (2020) proporcionou com a aplicação das oficinas um entendimento comum entre os órgãos públicos suecos estudados um entendimento comum sobre a implementação da Agenda 2030 e suas responsabilidades.

Diante do exposto, acredita-se que a integração de diferentes instrumentos de coleta de dados é necessária para analisar os processos de implementação da Agenda 2030 e de outros programas. Dentre os instrumentos mais utilizados, podemos destacar: i) os estudos de caso (para conhecer a realidade in loco), ii) a pesquisa documental (pois o tema demanda análise de documentos institucionais e legais); iii) entrevistas (com diversos stakeholders do setor público, privado e/ou sociedade civil), e iv) ferramentas de diagnóstico participativo (com multistakeholders). Destaca-se a importância dos diagnósticos participativos para a implementação da Agenda 2030, principalmente se considerarmos o caráter transversal do documento, isto é, a interação entre diferentes agentes promotores do desenvolvimento sustentável.

$\mathrm{O}$ uso dessas ferramentas participativas suscita o envolvimento de diferentes partes interessadas (stakeholders ou multistakeholders), quando se trabalha ou estuda questões relacionadas ao desenvolvimento sustentável. Tratando-se da Agenda 2030, a cooperação entre atores de diferentes escalas e contextos é essencial para a implementação dos ODSs (Stafford-Smith et al., 2016).

Neste sentido, Banerjee, Murphy e Walsh (2020) e Moreira (2018) apontam para a importância das parcerias multistakeholders na implementação da Agenda 2030, as quais devem apresentar um bom diálogo entre instituições de ensino superior, empresas privadas, sociedade civil e setor público. Neste quesito, os autores observam a falta de consciência sobre os ODSs na Irlanda e entre atores não estatais. Identificam ainda um baixo nível de consciência sobre a indivisibilidade e universalidade dos ODSs e como isso afeta a forma como os atores não estatais compreendam os objetivos, considerando que na maioria das vezes, os atores privados defendem somente os objetivos que se encaixam com seus objetivos organizacionais, executando os objetivos de forma separada. Segundo os autores, a fragmentação entre as partes interessadas dos objetivos pode criar desafios para que as organizações tenham uma visão holística dos ODS e seus princípios fundamentais de universalidade e 
indivisibilidade. Eles expõem ainda que algumas metas correm o risco de serem desvalorizadas, especialmente as metas ambientais quando os objetivos econômicos e sociais são priorizados pelos atores. Por fim, os autores apontam que o governo deve desempenhar um papel mais significativo na implementação dos ODSs e co-compartilhar a responsabilidade de alcançar os ODSs por meio de parcerias multistakeholders. Ou seja, ainda é preciso avançar no alinhamento e articulação da implementação de programas sustentáveis entre os diferentes stakeholders, cujas percepções e interesses são ainda grosseiramente diferentes.

Outro tema que chamou atenção foi a relação da governança global ou em rede com a implementação de programas sustentáveis em municípios, regiões ou países, como é apontado nos estudos de Palm e Lilja (2020), Moreira (2018) e Paz e Cuenca (2020). Trata-se dos processos e instituições, cujos atores sociais se organizam e tomam decisões a respeito de alguma questão específica, que, nos casos analisados, é a questão ambiental, podendo assim ser também chamada de governança ambiental. O que se nota é que a governança reforça a participação dos múltiplos atores envolvidos com a implementação de programas sustentáveis, assim como são entendidos nos conceitos de stakeholders ou multistakeholders. Por isso, Palm e Lilja (2020) defendem que a governança é vista como fundamental para ampliar a capacidade das autoridades em gerenciar os ajustes implicados na efetivação das metas da Agenda 2030, pois permite um trabalho conjunto e adaptativo em torno do alcance dos ODS.

Quando o foco das pesquisas é a gestão pública de municípios, os dois estudos analisados, o estudo de Fragoso, Arredondo e García (2016) realizados no Brasil e o de Oliveira, Trindade e Pereira (2015) feito no México, ressaltam a importância de políticas públicas para que sejam garantidas melhores condições socioeconômicas e ambientais da população. Esses dois trabalhos trouxeram a verificação de problemas de infraestrutura ou serviços básicos nos municípios analisados em relação ao tratamento de esgoto, disposição de resíduos sólidos, educação ambiental, serviços de saúde, segurança pública, moradias superlotadas, desemprego, dentre outros. São problemas comumente encontrados em países subdesenvolvidos como o Brasil e México e que devem ser levados em consideração na implementação de uma agenda sustentável, como apontam os trabalhos dos autores analisados.

E quando há a implementação de políticas públicas, observa-se a falta de ferramentas de monitoramento e controle, como observado na pesquisa de Moreira (2018) no Brasil. O autor considera de extrema importância o estabelecimento de ferramentas que monitorem e avaliem os impactos das políticas públicas a fim de melhorar a orientação dos processos institucionais na tomada de decisão.

Por fim, Paz e Cuenca (2020) demonstram preocupações quanto ao avanço do cumprimento da Agenda 2030, dada a crise global de saúde e seus impactos causados pela pandemia provocada pela Covid-19. Segundo os autores, a tarefa de implementação será cada vez mais difícil com a crise atual, considerando que os motores crescimento e distribuição de renda serão afetados e esforços adicionais deverão ser empregados para implementar políticas públicas eficazes que não deixem ninguém para trás. Os autores também reforçam a importância das relações multistakeholders em que a gestão pública não atue sozinha. Além disso, eles levantam duas questões que são de extrema importância para a implementação de programas sustentáveis na gestão pública, a necessidade de uma estratégia nacional de desenvolvimento sustentável e apoios financeiros que reforcem este compromisso político dos países.

Ao investigar a Gestão Pública, Agenda 2030 e Programas ambientais, percebe-se que apesar da temática ser atual, tendo em vista que a maioria dos artigos foram publicados em 2020, ainda são poucos os estudos que abordam o tema. Mesmo considerando o recorte dessa pesquisa em uma única base científica, a abrangência da Web of Science Coleção Principal poderia ser suficiente para resgatar mais estudos em torno do objeto pesquisado, já que ela reúne documentos de mais de 24000 periódicos científicos abrangendo mais de 254 temas disciplinares (WoS, 2019). Contudo, por ser um tema relativamente recente, é em parte justificável que a base não tenha recuperado tantos trabalhos. E dentre os trabalhos estudados percebe-se que muito se 
discute as estratégias de implementação da agenda e quais os atores responsáveis ou que contribuem para esta implementação, porém, ainda há uma ausência de mecanismos de avaliação e controle.

Esta ausência de mecanismos pode ser compreendida se considerarmos as dificuldades e os desafios no processo inicial de implementação da Agenda 2030 e de outros programas ambientais. Porém, mecanismos de avaliação são necessários em lugares com uma implementação já consolidada, visto que há muito o que se aprender e discutir com a implementação de um documento referência global para o desenvolvimento sustentável. Desta maneira, aponta-se a necessidade de estudos empíricos que retratam as experiências desses lugares, para que outras localidades possam implementar o documento e/ou outros programas de cidades sustentáveis e façam adaptações de acordo com as suas realidades locais.

\section{Considerações Finais}

Ao investigar o estado da arte sobre o tema gestão pública, Agenda 2030 e programas ambientais, observa-se que esta temática é emergente e atual, uma vez que a maioria dos estudos recuperados pela revisão integrativa foram publicados em 2020. Atribui-se a este fato, a publicação da Agenda 2030 em 2015 pela Organização das Nações Unidas (ONU), uma entidade reconhecida e respaldada internacionalmente e a cobrança cada vez mais intensa de que as autoridades públicas tomem providências quanto à pertinência dos problemas ambientais. Mas, os resultados apontam que ainda há espaço para uma maior exploração do tema, já que somente sete estudos foram selecionados da Web of Science Coleção Principal, base científica com um dos mais abrangentes repositórios científicos internacionais.

Os estudos resgatados pela revisão integrativa retratam a atuação da gestão pública na implementação da Agenda 2030 e/ou de outros programas ambientais. Percebe-se que há uma preocupação por parte dos órgãos públicos em promover caminhos assertivos, sejam eles por meio de aparatos legais e/ou por mecanismos ainda não consolidados, isto é, por meio de estratégias de implementação de determinados programas ou da agenda, que vêm sendo estudadas e discutidas no âmbito acadêmico. Dessa forma, destaca-se a necessidade de incutir ferramentas que permitam a avaliação e o controle do desempenho das metas voltadas ao desenvolvimento sustentável.

Os trabalhos indicam que o estudo de caso em que a triangulação de métodos é utilizada, incluindo nela ferramentas participativas, são os melhores meios de coletar dados e estudar fenômenos que abordam a questão ambiental, especificamente a Agenda 2030 ou outros Programas que versam sobre modelos de cidades sustentáveis. Apesar do papel primordial do setor público na implementação dos ODSs, são as parcerias multistakeholders entre governo, instituições de ensino superior, empresas privadas e sociedade civil, que se constituem como estratégias fundamentais para alcançar bons resultados nesta implementação. E quando considerados os países subdesenvolvidos, problemas de infraestrutura e serviços básicos devem ser tratados por qualquer agenda sustentável que seja implementada.

Sugere-se para estudos futuros, a análise de outros tipos de documentos publicados, além dos artigos e reviews e abranger outras bases de dados, a fim de ampliar a quantidade de pesquisas analisadas sobre o assunto ou ainda averiguar se as lacunas e boas práticas aqui verificadas são persistentes ou não. Dessa forma, uma maior abrangência das bases científicas e ampliação dos tipos de documentos analisados poderá preencher as lacunas identificadas referentes à gestão pública, Agenda 2030 e outros programas ambientais.

\section{Referências}

Adams, C., Borges, Z., Moretto, E., \& Futemma, C. (2020). Governança ambiental no Brasil: acelerando em direção aos objetivos de desenvolvimento sustentável ou olhando pelo retrovisor? Cadernos Gestão Pública e Cidadania, 25( 81), 1-13, e-81403. doi: 10.12660/cgpc.v25n81.81403 
Research, Society and Development, v. 10, n. 12, e203101220306, 2021

(CC BY 4.0) | ISSN 2525-3409 | DOI: http://dx.doi.org/10.33448/rsd-v10i12.20306

Botelho, L. L. R., Cunha, C. C. A., \& Macedo, M. (2011). O método da revisão integrativa nos estudos organizacionais. Gestão e Sociedade, 5(11), 121-136. Recuperado de https://www.gestaoesociedade.org/gestaoesociedade/article/view/1220/906. doi:10.21171/ges.v5i11.1220.

Bourscheidt, D. M. (2011). Economia e sustentabilidade: um estudo sobre indicadores de desenvolvimento sustentável (Dissertação de mestrado). Universidade Federal do Espírito Santo - UFES, Vitória, ES, Brasil.

Brandi, C. (2018). O papel das cidades: implementação da agenda 2030 e do acordo de Paris. In Fundação Getúlio Vargas, Cidades Sustentáveis (32a ed.). Rio de Janeiro e São Paulo: Cadernos FGV Projetos.

Bushe, G., \& Marshak, R. J. (2015). Dialogic organization development: The theory and practice of transformational change. Oakland, CA: Berrett-Koehler

Carson, R. (1991). Primavera Silenciosa. Tradução de Claudia Sant’Anna Martins. 1. ed. São Paulo: Gaia, 2010.

Comissão Mundial sobre Meio Ambiente e Desenvolvimento. Nosso futuro comum. (2a ed.). São Paulo: Fundação Getúlio Vargas.

Fragoso, J. T., Arredondo, A. C., \& García, E. D. G. (2016). Ciudad Rural Sustentable de Jaltenango: Aciertos y Desaciertos en el Ordenamiento Territorial. Revista Geográfica de América Central, 1(56), 209-234. Recuperado de https://www.redalyc.org/journal/4517/451746028009/html/. doi: 10.15359/rgac.1-56.9

Freitas, A. F., Freitas, A. F., \& Dias, M. M. (2013). O uso do diagnóstico rápido participativo (DRP) como metodologia de projetos de extensão universitária. Revista Em Extensão, 11(2), 69-81. http://www.seer.ufu.br/index.php/revextensao/article/view/20780/11882

Governo do Estado de São Paulo. (2021). Conheça o Programa Município VerdeAzul. Recuperado de https://www.infraestruturameioambiente.sp.gov.br/verdeazuldigital/

Januzzi, P. M., \& De Carlo, S. (2018). Da agenda de desenvolvimento do milênio ao desenvolvimento sustentável: oportunidades e desafios para planejamento e políticas públicas no século XXI. Revista Bahia Análises e Dados, 28(2), 6-27. http://www.cge.rj.gov.br/interativa/wp-content/uploads/2019/07/Textocomplementar-3.pdf

Montolli, C. A., Cançado, C. J., \& Claus, R. P. (2021). Gestão Pública, Governança e Meio Ambiente - a influência da Agenda 2030 e o Desenvolvimento Econômico Sustentável na formulação das políticas públicas no Estado de Minas Gerais. Revista Ciencias de la Documentación, 7(1), 44-68. http://cienciasdeladocumentacion.cl/pdf02/5\%20V7N1\%202021\%20CSDOCum.pdf

Moreira, A. C. S. (2018). Application of the Sustainable Logistics Plan in the Public Administration. Brazilian Journal of Operations \& Production Management, 15(1), 137-142. Recuperado de https://bjopm.emnuvens.com.br/bjopm/article/view/432/537. doi:10.14488/bjopm.2018.v15.n1.a12

Muiños, R. (2006). El diagnóstico participativo. San José, Costa Rica: Editorial Universitaria Estatal a Distancia.

Oliveira, E. C., Trindade, F. H., \& Pereira, R. S. (2015). Políticas Públicas Indutoras do Desenvolvimento Sustentável Local: Um Estudo Sobre o Programa Município VerdeAzul na Região do Grande ABC. Administração Pública e Gestão Social, 7(3), 109-119. https://periodicos.ufv.br/apgs/article/view/4493. doi: 10.21118/apgs.v7i3.531

Organização das Nações Unidas. (2015). Transformando nosso mundo: a Agenda 2030 para o desenvolvimento sustentável. Brasil.

Palm, K., \& Lilja, J. (2020). On the road to Agenda 2030 together in a complex alliance of Swedish public authorities. Environment, Development and Sustainability, 23, 9564-9580. Recuperado de https://link.springer.com/content/pdf/10.1007/s10668-020-01032-1.pdf. doi: 10.1007/s10668-020-01032-1

Patton, M. Q. (2002). Qualitative research and evaluation methods. (3a ed.). Thousand Oaks, California: Sage Publications.

Paz, E. C., \& Cuenca, M. C. S. (2020). Gobernanza Global y los Objetivos de Desarrollo Sostenible en España. Investigación y pensamiento crítico. Edición Especial Covid-19: Empresa, China y Geopolítica, 149-169. https://www.3ciencias.com/wp-content/uploads/2020/12/art-8-3c-emp-ee-covid19-diciembre-20202.pdf. doi:10.17993/3cemp.2020.edicionespecial1.149-169

Soberón, M., Sánchez-Chaparro, T., Urquijo, J., \& Pereira, D. (2020). Introducing an Organizational Perspective in SDG Implementation in the Public Sector in Spain: The Case of the Former Ministry of Agriculture, Fisheries, Food and Environment. Sustainability, 12(23), 1-20. Recuperado de https://www.mdpi.com/2071-1050/12/23/9959. doi: 10.3390/su12239959

Souza, N. J. (2012). Desenvolvimento Econômico. (6a ed.). São Paulo: Atlas.

Stafford-Smith, M., Griggs, D., Gaffney, O., Ullah, F., Reyer, B., Kanie, N., ... O’ Connell, D. (2016). Integration: the key to implementing the sustainable development goals. Sustainability Science, 12(6), 911-919. https://link.springer.com/article/10.1007/s11625-016-0383-3. doi: 10.1007/s11625-016-0383-3

United Nations. (2012). Declaration of the United Nations Conference on the Human Environment. Stockholm: United Nations.

Veiga, J. E. (2015). Para entender o desenvolvimento sustentável. (1a ed.). São Paulo: Editora 34.

Web of Science Coleção Principal - WoS. (2019). Web of Science: Master Journal List. https://supportclarivate.ez372.periodicos.capes.gov.br/ScientificandAcademicResearch/s/article/Web-of-Science-Master-Journal-List?language=en_US

Whittemore, R., \& Knafl, K. (2005). The integrative review: updated methodology. Journal of Advanced Nursing, Oxford, 52 (5), 546-553. 